\title{
A Cyclooxygenase-2 Inhibitor Ameliorates Behavioral Impairments Induced by Striatal Administration of Epidermal Growth Factor
}

\author{
Makoto Mizuno, ${ }^{1,2}$ Hidekazu Sotoyama, ${ }^{2}$ Eri Narita, ${ }^{2}$ Hiroki Kawamura, ${ }^{2}$ Hisaaki Namba, ${ }^{2}$ Yingjun Zheng, ${ }^{2}$ \\ Takeyoshi Eda, ${ }^{2}$ and Hiroyuki Nawa ${ }^{1,2}$ \\ ${ }^{1}$ Center for Transdisciplinary Research and 2Department of Molecular Neurobiology, Brain Research Institute, Niigata University, Niigata 951-8585, Japan
}

\begin{abstract}
Consistent with the hypothesis that neuroinflammatory processes contribute to the neuropathology of schizophrenia, the protein levels of epidermal growth factor (EGF) and its receptor ErbB1 are abnormal in patients with schizophrenia. To evaluate neuropathological significance of this abnormality, we established an animal model for behavioral deficits by administering EGF into the striatum and evaluated the effects of cyclooxygenase-2 (Cox-2) inhibitor celecoxib. Intracranial infusion of EGF into the striatum of adult male rats activated ErbB1 and induced neurobehavioral impairments observed in several schizophrenia models. Unilateral EGF infusion to the striatum lowered prepulse inhibition (PPI) in a dose-dependent manner and impaired latent learning of active shock avoidance without affecting basal learning ability. Bilateral EGF infusion similarly affected PPI. In contrast, EGF infusion to the nucleus accumbens did not induce a behavioral deficit. Intrastriatal EGF infusion also increased Cox-2 expression, elevated tyrosine hydroxylase activity, and upregulated the levels of dopamine and its metabolites. Subchronic administration of celecoxib (10 mg/kg, p.o.) ameliorated the abnormalities in PPI and latent learning as well as normalized dopamine metabolism. We conclude that this EGF-triggered neuroinflammatory process is mediated in part by Cox-2 activity and perturbs dopamine metabolism to generate neurobehavioral abnormalities.
\end{abstract}

Key words: inflammation; cyclooxygenase; EGF; schizophrenia; dopamine; prostaglandin

\section{Introduction}

In the CNS, epidermal growth factor (EGF) and structurally related EGF-like peptides (ErbB1 ligands) enhance survival and neurite outgrowth of midbrain dopaminergic neurons and are implicated in dopamine (DA)-related brain diseases such as Parkinson's disease and schizophrenia (Casper et al., 1994; Farkas and Krieglstein, 2002). EGF content is decreased and EGF receptor (ErbB1) levels are increased in the striatum of schizophrenia patients (Futamura et al., 2002). Genetic linkage studies may also support the contribution of EGF to schizophrenia etiology or pathology (Anttila et al., 2004; Hanninen et al., 2007). EGF and other EGF homologs were isolated as cell growth factors and implicated in the progression of cancer (Ackerman et al., 2004; Slice et al., 2005; Liao et al., 2006). Binding of EGF to ErbB1 enhances the expression of inducible prostaglandin synthetase [cyclooxygenase 2 (Cox-2)] and triggers a variety of inflammatory processes (Slice et al., 2005; Liao et al., 2006). Therefore, EGF and other homologs are implicated in the pathogenesis of inflam-

Received Jan. 18, 2007; revised July 9, 2007; accepted July 31, 2007.

This work was supported by a grant-in-aid from the Health and Labor Sciences Research Grants, a grant-in-aid for Basic Scientific Research B, Core Research for Evolutional Science and Technology from the Japan Science and Technology Corporation, and a grant for Promotion of Niigata University Research Projects. We thank Dr. K. Kobayashi for biochemical advice.

Correspondence should be addressed to Hiroyuki Nawa, Department of Molecular Neurobiology, Brain Research Institute, Niigata University, Niigata 951-8585, Japan. E-mail: hnawa@bri.niigata-u.ac.jp.

DOI:10.1523/JNEUROSCI.2368-07.2007

Copyright $\odot 2007$ Society for Neuroscience 0270-6474/07/2710116-12\$15.00/0 matory diseases such as rheumatoid arthritis. Subsequently produced prostaglandins bind G-protein-coupled receptors and stimulate production of EGF or other ErbB1 ligands by ectodomain shedding (Pai et al., 2002; Han et al., 2006). This feedforward loop between ErbB1 ligands and Cox-2 expression promotes cancer cell proliferation and inflammatory progression (Huh et al. 2003). In contrast, the central actions of EGF or other ErbB1 ligands on the neuroinflammatory processes are poorly understood.

Neuroinflammation is implicated in etiology or neuropathology of not only neurodegenerative diseases but also a number of psychiatric disorders (Das and Khan, 1998; Heleniak and O’Desky, 1999). Patients with schizophrenia often exhibit impaired autoimmune responses and abnormal levels of cytokines (Licinio et al., 1993; Lin et al., 1998; Toyooka et al., 2003). Interestingly, there is also a reverse correlation between neuroinflammation and psychiatric symptoms. Various psychiatric symptoms develop during or after cytokine therapy for cancer, viral infection, and anemia (Denicoff et al., 1987; McDonald et al., 1987). Thus, cytokine-mediated inflammatory reactions may in certain circumstances evoke psychiatric symptoms. Based on this hypothesis, preclinical trials of nonsteroidal anti-inflammatory drugs on patients with schizophrenia are underway (Muller et al., 2002, 2004; Riedel et al., 2005). Tetracycline, an antibiotic that possesses anti-inflammatory activity, improves the positive and negative syndrome scale (PANSS) of schizophrenia patients (Miyaoka et al., 2007). Thus, anti-inflammatory medication aug- 
ments therapies for neuropsychiatric conditions, although the pharmacological mechanisms underlying their antipsychotic actions are not fully characterized.

To study a potential neuroinflammatory role of the striatal EGF signal in a schizophrenia model, we examined the neurobehavioral consequences of striatal EGF administration as well as its effects on Cox-2 expression in rats. Given the biological activity of EGF on dopaminergic neurons, we focused on the neurochemical markers and animal behaviors related to dopaminergic dysfunctions and/or schizophrenia, prepulse inhibition (PPI) of startle, and latent inhibition (Braff et al., 2001; Geyer et al., 2001; Jeanblanc et al., 2003; Peterschmitt et al., 2005). We also evaluated the effects of acute and subchronic inhibition of Cox- 2 in conjunction with dopamine metabolism and behavioral performance.

\section{Materials and Methods}

Subjects. Male Sprague Dawley rats (7-8 weeks old, 300-380 g body weight, 190 rats in total) were purchased from SLC (Shizuoka, Japan) and maintained under a $12 \mathrm{~h}$ light/dark cycle (lights on from 7:00 A.M. to 7:00 P.M.) with access to food and water ad libitum. Before testing, rats were habituated to experimental rooms and experimenters with daily handling for at least 1 week. Surgical operation and behavioral tests were performed during the day cycle. Recombinant human EGF (Higeta Syoyu, Chiba, Japan) was dissolved in saline and intracranially administered from an osmotic minipump (see below). All of the animal experiments described here were performed in accordance with the Animal Use and Care Committee guidelines of Niigata University and the Guiding Principles for the Care and Use of Laboratory Animals approved by the Japanese Pharmacological Society.

Surgical procedure and subchronic EGF administration. Rats (8-9 weeks old) were anesthetized with sodium pentobarbital (50 mg/kg, i.p.; Dainippon Pharmaceutical, Suita, Osaka, Japan). After confirming the deep anesthesia, each rat was mounted on a stereotaxic apparatus (Narishige, Tokyo, Japan) with the upper incisor bar set $3.0 \mathrm{~mm}$ below the interaural line. The skull was exposed and a hole drilled for unilateral placement of intracerebral cannula guides into either the striatum or nucleus accumbens. A cannula (30 gauge; Terumo, Tokyo, Japan) was implanted in the striatum $(0.5 \mathrm{~mm}$ posterior and $3.0 \mathrm{~mm}$ right lateral measured from the bregma, $5.5 \mathrm{~mm}$ below the skull) or in the nucleus accumbens $(1.6 \mathrm{~mm}$ anterior and $2.0 \mathrm{~mm}$ right lateral measured from the bregma, $7.0 \mathrm{~mm}$ below the skull), glued to the skull, and connected to an Alzet osmotic minipump (model 2002, a 2 week type; Alza, Palo Alto, CA) by medicalgrade vinyl tubing. For bilateral EGF infusion, cannulas were implanted in both hemispheres of the striatum $(0.5 \mathrm{~mm}$ posterior and $\pm 3.0 \mathrm{~mm}$ lateral measured from the bregma, $5.5 \mathrm{~mm}$ below the skull) and connected to two minipumps. A minipump was filled with human recombinant EGF $(0.005,0.05$, or $0.15 \mathrm{mg} / \mathrm{ml} ; 0.2 \mathrm{ml}$ total) or $0.9 \%$ saline (vehicle) and implanted subcutaneously in the nape of the neck. Either saline or EGF was administered continuously at a rate of $0.5 \mu \mathrm{l} / \mathrm{h}$ from the minipump. Unless the dose of EGF is otherwise specified, each minipump contained $30 \mu \mathrm{g}$ of protein and EGF was infused at a rate of 75 $\mathrm{ng} / \mathrm{h}$. The scalp incision was closed with surgical staples and treated with a topical antiseptic, Cefmetazon $(50 \mathrm{mg} / \mathrm{d}$; Sankyo Pharmaceuticals, Tokyo, Japan). The cannula position and EGF content in a pump were confirmed after completion of behavioral tests.

Schedule of behavioral testing, drug treatment, and dissection. Rats were subjected to behavioral tests after a recovery period at least $7 \mathrm{~d}$ in length after minipump implantation but before the minipump was depleted of EGF (14 d after surgery). The saline- or EGF-infused rats were additionally treated with the Cox-2 inhibitor celecoxib. Celecoxib $(10 \mathrm{mg} / \mathrm{kg}$; Pfizer, New York, NY) was dissolved in saline and administered once a day orally with the aid of oral zonde for rats (Natusme Seisakusho, Tokyo, Japan). The celecoxib treatment was performed daily 3-4 d after pump implantation to days 11-12 after surgery. Behavioral tests followed this treatment regimen. To minimize the acute influences of celecoxib, examinations were performed at least $20 \mathrm{~h}$ after treatment unless it is otherwise specified.

To avoid interactions between independent behavioral tests, rats were subjected to one of the scheduled tests only once. The sole exception to this testing strategy was that rats that had been subjected to PPI testing were also tested for context learning. After behavioral evaluation, most of rats were killed, and tissue was harvested for neurochemical analysis or histochemistry (see below). Tissue samples for basal monoamine turnover were harvested from rats examined for effects of EGF doses on PPI. The effects of celecoxib on monoamine turnover were examined with tissue from animals tested for latent learning. The rats receiving EGF in the nucleus accumbens were fixed for histochemistry after PPI testing. To minimize the influences of the behavioral tests on the levels of monoamines, their extraction was performed at least $6 \mathrm{~h}$ after the end of the test. All other tissue samples were prepared from the rats that did not receive behavioral testing. Animals that exhibited any symptoms of infection around the cannula or the incision site were removed from study. In total, eight experimental groups representing 180 rats were analyzed in the present study.

Histochemistry. Rats receiving EGF infusion were transcardially perfused with $4 \%$ paraformaldehyde in a $0.1 \mathrm{M}$ PBS, $\mathrm{pH}$ 7.4. Coronal sections (15 $\mu \mathrm{m}$ thick) were cut from frozen brains and immunostained with antibodies directed against human EGF (1:200; Santa Cruz Biotechnology, Santa Cruz, CA) or Cox-2 (1:500; Cayman Chemical Ann Arbor, $\mathrm{MI})$. The immunoreactivity was visualized with biotinylated anti-rabbit Ig antibody coupled with the ABC method (Vector Laboratories, Burlingame, CA).

Immunoblot analysis. Rat receiving EGF or saline were killed by carbon dioxide exposure, and the brains were dissected out. Samples of striatum were homogenized by ultrasonication in $2 \times$ sample loading buffer $(100$ mм Tris- $\mathrm{HCl}$ buffer, $\mathrm{pH}$ 6.8, 4\% SDS, $100 \mathrm{~mm}$ dithiothreitol, 20\% glycerol, and $0.0001 \%$ bromophenol blue). Protein extracts ( 5 or $50 \mu \mathrm{g}$ per lane) were separated by SDS-PAGE on $8 \%$ gels and transferred to nitrocellulose membranes by electrophoresis. Membranes were probed with antibodies directed against ErbB1 (1:1000; Santa Cruz Biotechnology). Alternatively, immunoblots were probed with anti-phosphorylated ErbB1(1:1000), anti-ErbB2 (1:2000), anti- $\mathrm{D}_{2}$ receptor (1:1000), antidopamine transporter (DAT) (1:1000), anti-Cox-2 (1:1000; all from Santa Cruz Biotechnology), anti- $\mathrm{D}_{1}$ receptor (1:1000; Sigma, St. Louis, $\mathrm{MO})$, anti-synaptophysin (1:1000; NeoMarkers, Fremont, CA), or antityrosine hydroxylase (1:1000; Chemicon, Temecula, CA) antibodies. The immunoreactivity on the membrane was detected by chemiluminescence (ECL kit; GE Healthcare, Little Chalfont, UK).

The activity of tyrosine hydroxylase. Striatal tissue was homogenized in lysis buffer [0.32 м sucrose, 20 mм Tris- $\mathrm{HCl}, \mathrm{pH}$ 7.3, 1 mm dithiothreitol, and protease inhibitor cocktail (Complete Mini; Roche Diagnostic, Mannheim, Germany)]. Protein homogenates (20 $\mu \mathrm{l} /$ tube) were incubated with $180 \mu \mathrm{l}$ of reaction buffer [0.2 mM L-tyrosine, $0.2 \mathrm{M}$ sodium acetate, $0.1 \mathrm{~m}$ 2-mercaptoethanol, $0.5 \mathrm{~mm}$ ferrous sulfate heptahydrate, 1 mM 6-methyl-5,6,7,8-tetrahydropterin (Sigma), $0.2 \mathrm{mg} / \mathrm{ml}$ catalase (Roche Diagnostic), and $50 \mu \mathrm{M} s(-)$-carbidopa (Wako Chemical, Tokyo, Japan)] at $37^{\circ} \mathrm{C}$ for $10 \mathrm{~min}$. The enzyme reaction was terminated on ice with a stop solution $(250 \mu \mathrm{l})[1 \mathrm{M}$ perchloric acid, $0.2 \mathrm{M}$ EDTA, and 1 mм $\alpha$-methyldopa (an internal standard)]. After 15 min incubation on ice, $150 \mu \mathrm{l}$ of $1 \mathrm{M} \mathrm{K}_{2} \mathrm{CO}_{3}$ and $1 \mathrm{ml}$ of $0.1 \mathrm{M}$ Tris- $\mathrm{HCl}$, $\mathrm{pH} 8.5$, were added, and the supernatant was collected. The product of 3,4-dihydroxy-Lphenylalanine (L-DOPA) was absorbed with alumina (aluminumoxide 90 active acidic; Merck, Darmstadt, Germany) and then eluted with $0.5 \mathrm{M}$ $\mathrm{HCl}(0.8 \mathrm{ml} /$ tube). Concentrations of L-DOPA were determined by HPLC with electrochemical detection ECD (see below) (mobile phase: 50 mu trisodium citrate, $25 \mathrm{~mm} \mathrm{NaH}_{2} \mathrm{PO}_{4}, 100 \mu \mathrm{M}$ EDTA, and 1\% methanol, $\mathrm{pH} 2.8$ ).

Measurement of acoustic startle and prepulse inhibition. Acoustic startle and PPI responses were measured in a startle chamber (SR-Lab Systems; San Diego Instruments, San Diego, CA) adapted for rats (Braff and Geyer, 1990; Swerdlow and Geyer 1998; Swerdlow et al., 2001). The chosen paradigm was adapted and modified from Braff and Geyer (1990) and used to assess startle amplitude, habituation, and PPI response with acoustic stimuli of $120 \mathrm{~dB}$, a single prepulse interval (100 ms), and three 
Table 1. Effects of striatal EGF infusion on monoamine contents and turnover

\begin{tabular}{lccc}
\hline & Saline $(0 \mu \mathrm{g})$ & $3 \mu \mathrm{g}$ of EGF & $10 \mu \mathrm{g}$ of EGF \\
\hline 5-HIAA & $326 \pm 69$ & $428 \pm 105$ & $480 \pm 62$ \\
5-HT & $17,200 \pm 4200$ & $25,800 \pm 7610$ & $24,600 \pm 2250$ \\
DA & $109,000 \pm 2690$ & $109,000 \pm 37,900$ & $157,000 \pm 12,300$ \\
DOPAC & $1220 \pm 213$ & $1230 \pm 373$ & $20,200 \pm 3320$ \\
HVA & $2400 \pm 580$ & $3440 \pm 1140$ & $1850 \pm 152$ \\
EP & $47 \pm 5$ & $43 \pm 4$ & $5580 \pm 423^{* *}$ \\
NE & $404 \pm 62$ & $590 \pm 159$ & $47 \pm 3$ \\
\hline
\end{tabular}

Different doses of EGF were unilaterally administered to rat striatum from a minipump for $10 \mathrm{~d}$, and monoamines were extracted from the ipsilateral hemisphere of the striatum. The levels of DA, DOPAC, HVA, serotonin (5-HT), and 5 -hydroxyindoleacetic acid (5-HIAA) in the striatum were determined by HPLC-ECD as described previously (Futamura et al., 2003). The total amounts of EGF in a minipump were given in this table. Data represent means \pm SEM (picomoles per gram of wet tissue; $n=5-6$ animals each). ${ }^{*} p<0.05,{ }^{* *} p<0.01$ by Fisher's LSD. EP, Epinephrine; NE, norepinephrine.

different prepulse intensities [5, 10, and $15 \mathrm{~dB}$ above background noise (white noise, $70 \mathrm{~dB}$ )]. Each rat was placed in the startle chamber and initially acclimatized for 5 min with background noise alone. The rat was then subjected to 50 startle trials, each trial consisting of one of five conditions: (1) a $40 \mathrm{~ms}, 120 \mathrm{~dB}$ noise burst presented alone; (2-4) a 40 $\mathrm{ms}, 120 \mathrm{~dB}$ noise burst after prepulses by $100 \mathrm{~ms}$ ( $20 \mathrm{~ms}$ noise burst) that were 5,10 , or $15 \mathrm{~dB}$ above background noise (i.e., 75,80 , or $85 \mathrm{~dB}$ prepulse, respectively); or (5) no stimulus (background noise alone), which was used to measure baseline movement in the chamber. In PPI tests, these five trial types (1-5) were each repeated eight times in a pseudorandom order to give 40 trials. Each trial type was presented once within a block of five trials. At the beginning and end of the PPI test, five consecutive trials of condition 1 were presented to assess habituation during sessions. The intertrial interval was $15 \mathrm{~s}$. Analysis of PPI was based on the mean of the eight trials for each trial type. The percentage PPI of a startle response was calculated as follows:

$$
\text { PPI }=100-\frac{(\text { prepulse and pulse stimulus trials }}{\text { pulse-alone trials }- \text { no stimulus trials }} .
$$

Active-avoidance learning and latent inhibition. Rats were given 60 trials of two-way active-avoidance conditioning (10 trials per block) (Salmi et al., 1994; Futamura et al., 2003). Active-avoidance testing was conducted in an automated shuttle box (Muromachi-kiki, Tokyo, Japan) subdivided into two virtual compartments with independently electrified stainless-steel bars as floors. One trial consisted of a buzzer tone [conditioning stimulus (CS)] and an electric shock [unconditioning stimulus (US)]. The CS was an $80 \mathrm{~dB}$ tone for $10 \mathrm{~s}$. The US was a $2 \mathrm{~s}$ positive half-wave constant current of $0.5 \mathrm{~mA}$ intensity. When the CS was on, the animals had to cross to the other side of the shuttle box apparatus (avoidance response) to turn the CS off and to avoid the US. The US was initiated if the animal failed to make an escape response. The intertrial schedule had a variable interval (10-90 s). Animals in non-preexposed (NPE) group were directly subjected to the above conditioning. One day before the conditioning, rats in the preexposed (PE) group were placed in the automated shuttle box and exposed to the buzzer tones (CS) with the above protocol but without receiving electric stimuli (US). Preexposed to CS were followed by the final treatment with celecoxib at an interval of $1 \mathrm{~h}$.

Context fear learning. The test paradigm of contextual conditioning was based on a work by Matus-Amat et al. (2004). Rats were transported to the laboratory at least $30 \mathrm{~min}$ before fear conditioning. Rats were placed in a shock chamber with a stainless-steel grid floor $(21.5$ $\mathrm{cm}$ width $\times 20.5 \mathrm{~cm}$ depth $\times 30 \mathrm{~cm}$ height box; Ohara Medical Industry, Tokyo, Japan) for 2 min to monitor baseline movement/ freezing and were then exposed to $0.8 \mathrm{~mA}$ electric shocks $(2 \mathrm{~s}$ duration, twice at an interval of $1 \mathrm{~min}$ ). One day after conditioning, rats were returned to the same chamber. The time spent freezing was recorded by a video camera and averaged every $30 \mathrm{~s}$ with the aid of an imaging software (Ohara Medical Industry). The final treatment with celecoxib was done $1 \mathrm{~d}$ before conditioning.

Quantification of dopamine and its metabolites. The levels of DA, L-DOPA, 3,4-dihydroxyphenylacetic acid (DOPAC), homovanillic acid (HVA), serotonin, 5-hydroxyindoleacetic acid, epinephrine, and norepinephrine were determined by HPLC-ECD as described previ- ously (Futamura et al., 2003). Frontal cortex and striatum were dissected out from rats, weighed, and then immediately homogenized by ultrasonication in $0.5 \mathrm{ml}$ of $0.1 \mathrm{M}$ perchrolic acid containing $0.1 \mathrm{~mm}$ EDTA and $250 \mathrm{~nm}$ isoproterenol as an internal standard. The homogenate was placed on ice for $30 \mathrm{~min}$ and then centrifuged at $10,000 \times g$ for $10 \mathrm{~min}$. The HPLC-ECD system consisted of a pump (model LC-10ADVP; Shimadzu, Kyoto, Japan), an automatic sample injector (model SIL-10ADVP; Shimadzu), a C18 column (model CA-5ODS, $4.6 \times 150 \mathrm{~mm}$; Eicom, Kyoto, Japan), and an electrochemical detector with a glassy carbon-working electrode (model ECD-300; Eicom). The mobile phase consisted of $50 \mathrm{~mm}$ trisodium citrate, $25 \mathrm{~mm}$ $\mathrm{NaH}_{2} \mathrm{PO}_{4}, 0.03 \mathrm{~mm}$ EDTA, $10 \mathrm{~mm}$ diethylamine, $3 \mathrm{~mm}$ octanesulfonic acid sodium salt, $6 \%$ methanol, and $1 \%$ dimethylacetamide, $\mathrm{pH} 3.2$. The current produced was monitored using an EPC-300 (Eicom).

Statistical analysis. Results were expressed as means \pm SEM. Statistical differences were determined by ANOVA. When univariate data were obtained only from two groups, a two-tailed $t$ test was used for comparison. Behavioral scores were initially analyzed using multiple ANOVA with EGF administration (two levels or four doses), celecoxib treatment (two levels), and/or preexposure to CS (two levels) as between-subject factors and prepulse magnitude (three levels) or block (six) as a within-subject factor. Interaction of a within-subject factor with between-subject factors was estimated by analysis of covariance and multivariate analysis of variance with Pillai compensation. Because the initial analyses yielded significant factorial interaction, the data were separated to avoid the interaction for the final analyses. Subsequently, a Fisher's least significant difference (LSD) test was applied to absolute behavioral values as a post hoc test of multiple comparisons. A $p$ value $<0.05$ was regarded as statistically significant. Statistical analysis was performed using Statview software (SAS Institute, Cary, NC). $n$ values in parentheses represent the number of animals used.

\section{Results}

Effects of intrastriatal EGF administration on monoamine metabolism and sensorimotor gating

Peptides in the EGF family exert neurotrophic effects on dopaminergic neurons both in vitro and in vivo (Casper et al., 1994; Farkas et al., 2002; Futamura et al., 2003; Iwakura et al., 2005) and increase the activity of tyrosine hydroxylase (Halegoua and Patrick, 1980; Anastasiadis et al., 1997). To investigate the central actions of EGF, we unilaterally administered various concentrations of EGF to the striatum of rats with an osmotic minipump and then determined the levels of monoamines and their metabolites in brain tissue. Subchronic EGF infusion to the striatum increased the levels of dopamine $\left(F_{(3,17)}=3.48 ; p=0.039\right)$ and its metabolites DOPAC and $\operatorname{HVA}\left(F_{(3,17)}=4.03, p=0.025\right.$ for DOPAC and $F_{(3,17)}=5.27, p=0.009$ for HVA) in the striatum in a dose-dependent manner (Table 1). Post hoc comparisons revealed that only the highest dose of EGF (30 $\mu \mathrm{g} / \mathrm{pump}, 1.8 \mu \mathrm{g} / \mathrm{d}$ ) significantly increased the levels of dopamine, DOPAC, and HVA. In contrast to the effects on the striatum, EGF did not alter 


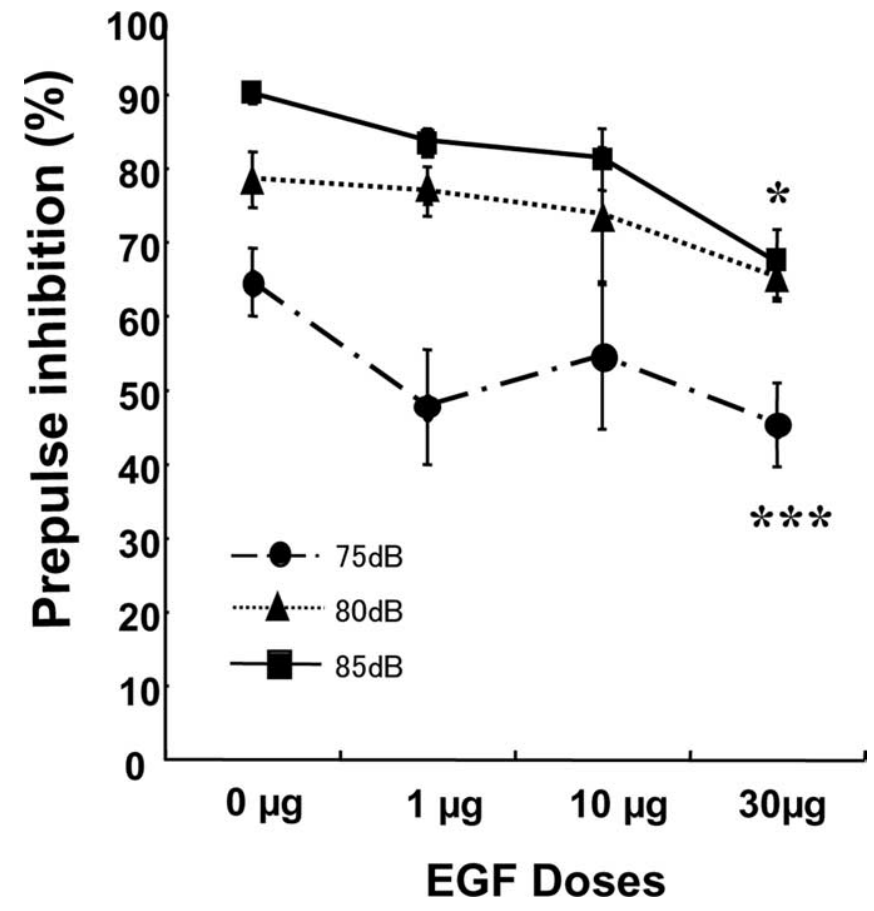

Figure 1. EGF dose dependency of PPI deficits. Different doses of human $\operatorname{EGF}(0,1,10$, and 30 $\mu \mathrm{g} /$ pump, equivalent to $0,0.06,0.6$, and $1.8 \mu \mathrm{g} / \mathrm{d}$ ) were administered to the striatum of male adult rats from an osmotic minipump for $10 \mathrm{~d}$. PPI with 75,80 , and $85 \mathrm{~dB}$ prepulse stimuli was measured and compared between doses. Values indicate means \pm SEM ( $n=7-10$ each). ${ }^{*} p<0.05,{ }^{* * *} p<0.001$ compared with vehicle-infused controls by Fisher's LSD.

the concentrations of dopamine and its metabolites in frontal cortex (data not shown).

To evaluate the neurobehavioral consequences of intrastriatal EGF infusion, we also monitored the dose-dependent effects of EGF on PPI (Fig. 1). A two-way repeated ANOVA for PPI revealed significant main effects of EGF dose $\left(F_{(3,30)}=5.58 ; p=\right.$ $0.0036)$ and prepulse amplitude $\left(F_{(2,60)}=58.8 ; p<0.0001\right)$ that were independent. Post hoc analysis indicated that the maximum dose of EGF (30 $\mu \mathrm{g} /$ pump) significantly reduced PPI with 75 and $85 \mathrm{~dB}$ prepulse tones. Therefore, EGF administered to the striatum elevated dopamine turnover and reduced PPI in a dosedependent manner. In subsequent experiments, rats received the highest dose of EGF (30 $\mu \mathrm{g} / \mathrm{pump}, 1.8 \mu \mathrm{g} / \mathrm{d}$ ).

\section{Intrastriatal administration of EGF induces}

Cox-2 immunoreactivity

After subchronic EGF infusion, distributions of EGF in the brain were examined by immunohistochemistry with an anti-EGF antibody. EGF appeared to diffuse through the striatal region efficiently. There was marked EGF immunoreactivity in the ipsilateral striatum as well as in the somatosensory neocortex along the route of the cannula (Fig. 2A). No immunoreactivity for EGF was detected in animals receiving an infusion of saline (data not shown). Because EGF is a potent Cox-2 inducer (Slice et al., 2005; Liao et al., 2006), we also examined Cox-2 immunoreactivity in EGF-infused rats. EGF increased the immunoreactivity of Cox-2 in the striatum and around the ventricular wall, relative to vehicle-infused animals (Fig. $2 B-E$ ).

\section{Effects of EGF depletion and bilateral EGF administration on PPI}

To examine the reversibility of the effect of EGF on PPI, first we confirmed its effects by administering rats EGF for $7 \mathrm{~d}$ and then
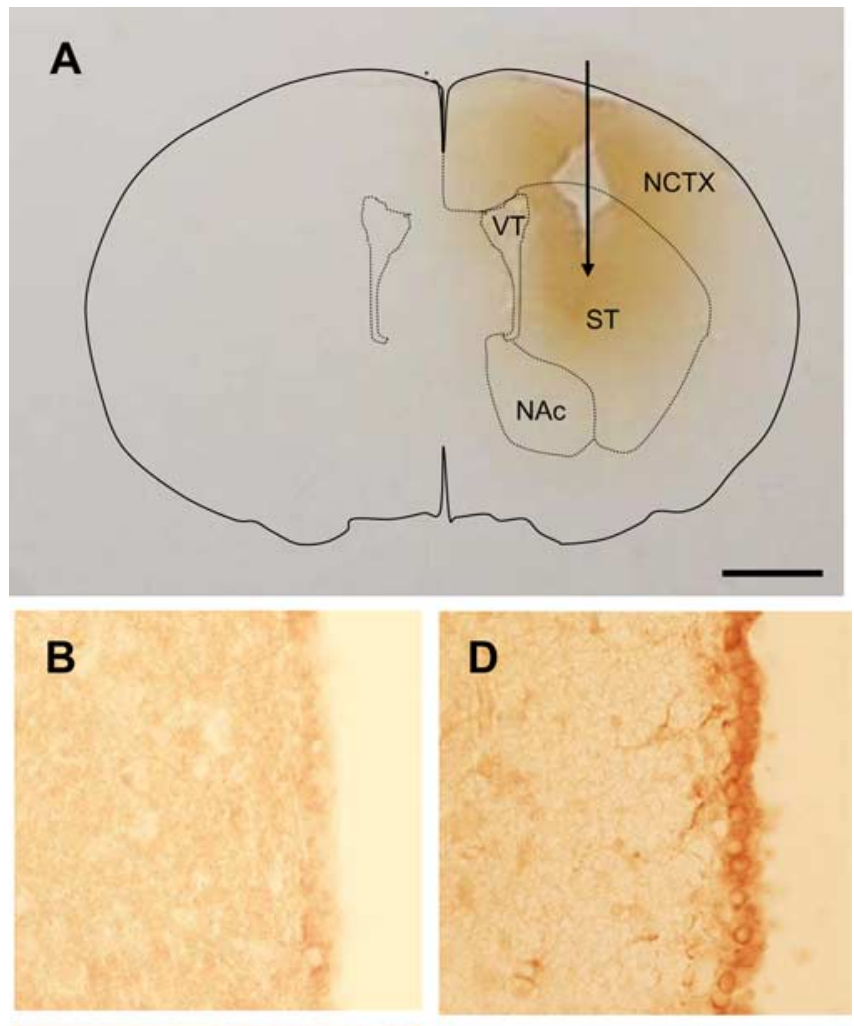

C

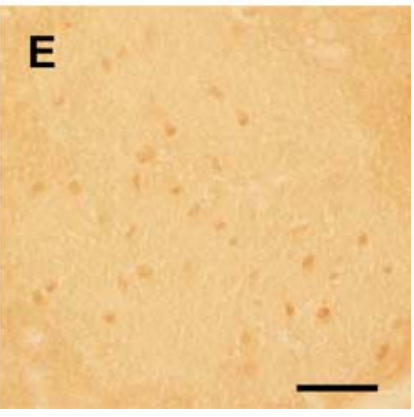

Figure 2. Distributions of EGF and Cox-2 immunoreactivity after subchronic striatal administration of EGF. $\boldsymbol{A}$, The efficacy of EGF infusion was examined by immunohistochemistry. EGF was administered to the striatum of adult male rats from an osmotic minipump ( $30 \mu \mathrm{g} / \mathrm{pump}$ ) for $8 \mathrm{~d}$. Coronal sections along the cannula route were immunostained with an anti-human EGF antibody. $\boldsymbol{B}-\boldsymbol{E}$, The distribution of Cox-2 immunoreactivity was examined in vehicle-infused ( $\boldsymbol{B}$, $\boldsymbol{C})$ and EGF-infused $(\boldsymbol{D}, \boldsymbol{E})$ animals. The most marked increase in Cox-2 immunoreactivity was observed around the lateral ventricle $(\boldsymbol{D})$ and in the striatum $(\boldsymbol{E})$ of the ipsilateral hemisphere. NCTX, Neocortex; ST, striatum; VT, lateral ventricle; NAc, nucleus accumbens. Scale bars: $\boldsymbol{A}, 250$ $\mu \mathrm{m} ; \boldsymbol{B}-\boldsymbol{E}, 30 \mu \mathrm{m}$. An arrow indicates the cannula position.

monitoring acoustic startle responses to $120 \mathrm{~dB}$ noise and PPI (Fig. 3). EGF infusion did not alter the startle response to $120 \mathrm{~dB}$ noise when compared with vehicle-infused animals (two tailed $t$ test, $p=0.072$ ) (Fig. $3 A$ ). We confirmed the significant main effects of EGF $\left(F_{(1,28)}=6.59 ; p=0.016\right)$ on PPI (Fig. 3C). Post hoc analysis detected a significant decrease in PPI levels with the 85 $\mathrm{dB}$ prepulse tone. Ten days after cessation of EGF administration, there was no significant difference in startle amplitudes and PPI levels between EGF-treated and vehicle-treated animals, demonstrating that the effects of EGF are reversible (Fig. $3 B, D$ ).

To examine whether the effect on PPI were a consequence of unilateral infusion of EGF, we assessed bilateral effects of EGF infusion on PPI. We subchronically administered EGF to the striatum in both hemispheres from two osmotic minipumps and measured acoustic startle responses to $120 \mathrm{~dB}$ noise (Fig. 4A,B). 

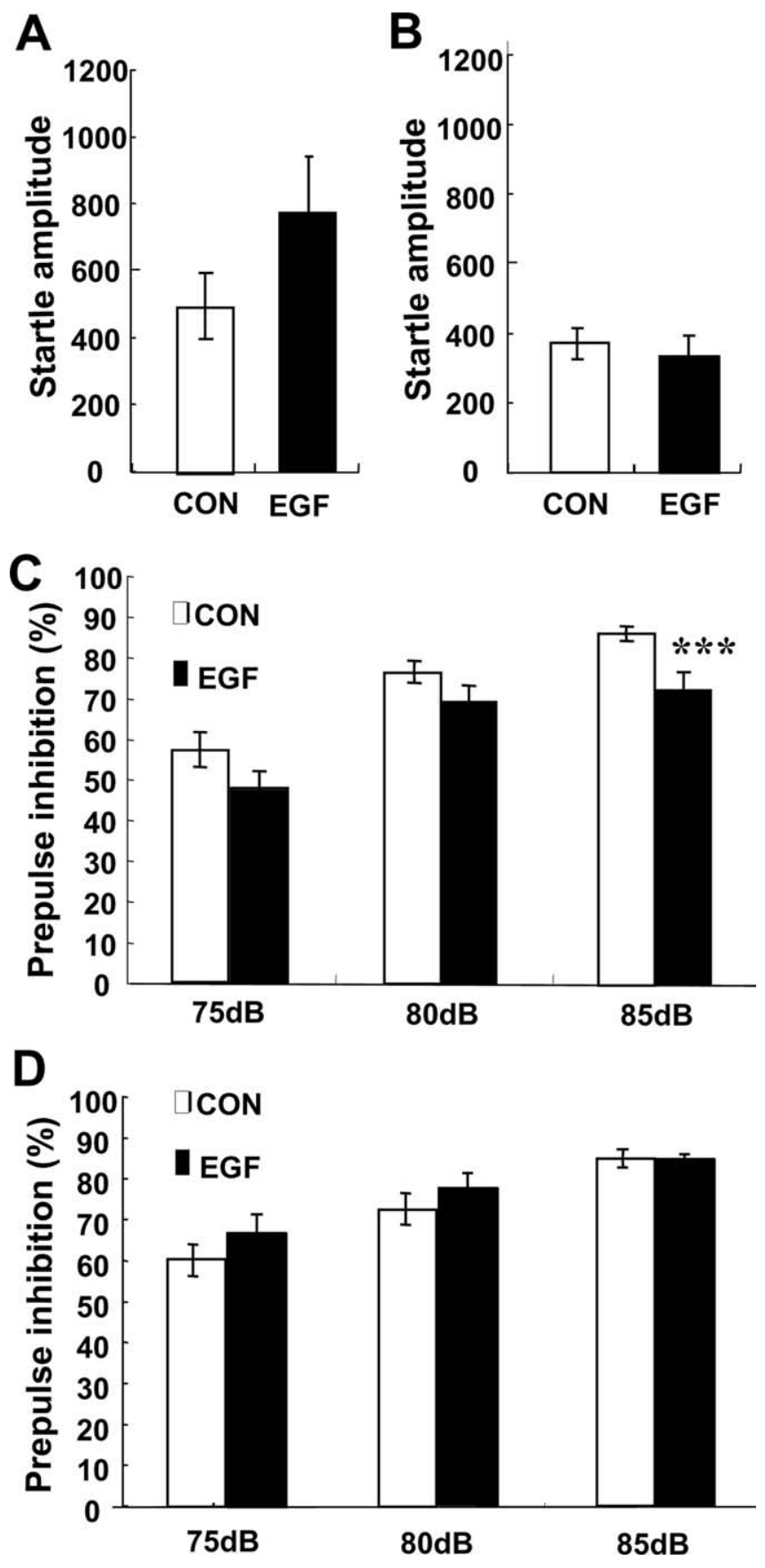

Figure 3. Effects of EGF depletion on acoustic startle response and prepulse inhibition. $A, B$, Acoustic startle response of vehicle-infused control (CON; open box) and EGF-infused (filled box) rats was measured on day 8 of EGF administration ( $30 \mu \mathrm{g} / \mathrm{pump}$ ) $(\boldsymbol{A})$ and $10 \mathrm{~d}$ after completion of EGF administration (B). C, D, Simultaneously, PPI of vehicle-infused control (open box) and EGF-infused (filled box) animals with 75,80 , and $85 \mathrm{~dB}$ prepulse stimuli was measured during EGF administration $(\boldsymbol{C})$ and after completion of EGF administration $(\boldsymbol{D})$. Error bars indicate means \pm SEM $\left(n=15\right.$ each). ${ }^{* * *} p<0.001$ by Fisher's LSD.

EGF infusion to the striatum in both hemispheres did not significantly alter the startle response to $120 \mathrm{~dB}$ noise when compared with vehicle-infused animals. A two-way repeated ANOVA revealed significant main effects of bilateral EGF infusion $\left(F_{(1,10)}=\right.$ $7.58 ; p=0.020)$ and prepulse amplitude $\left(F_{(2,20)}=19.5 ; p<\right.$ 0.001 ) on PPI without interaction. Post hoc analysis identified significant decreases in PPI with the 75 and $80 \mathrm{~dB}$ prepulse tones.

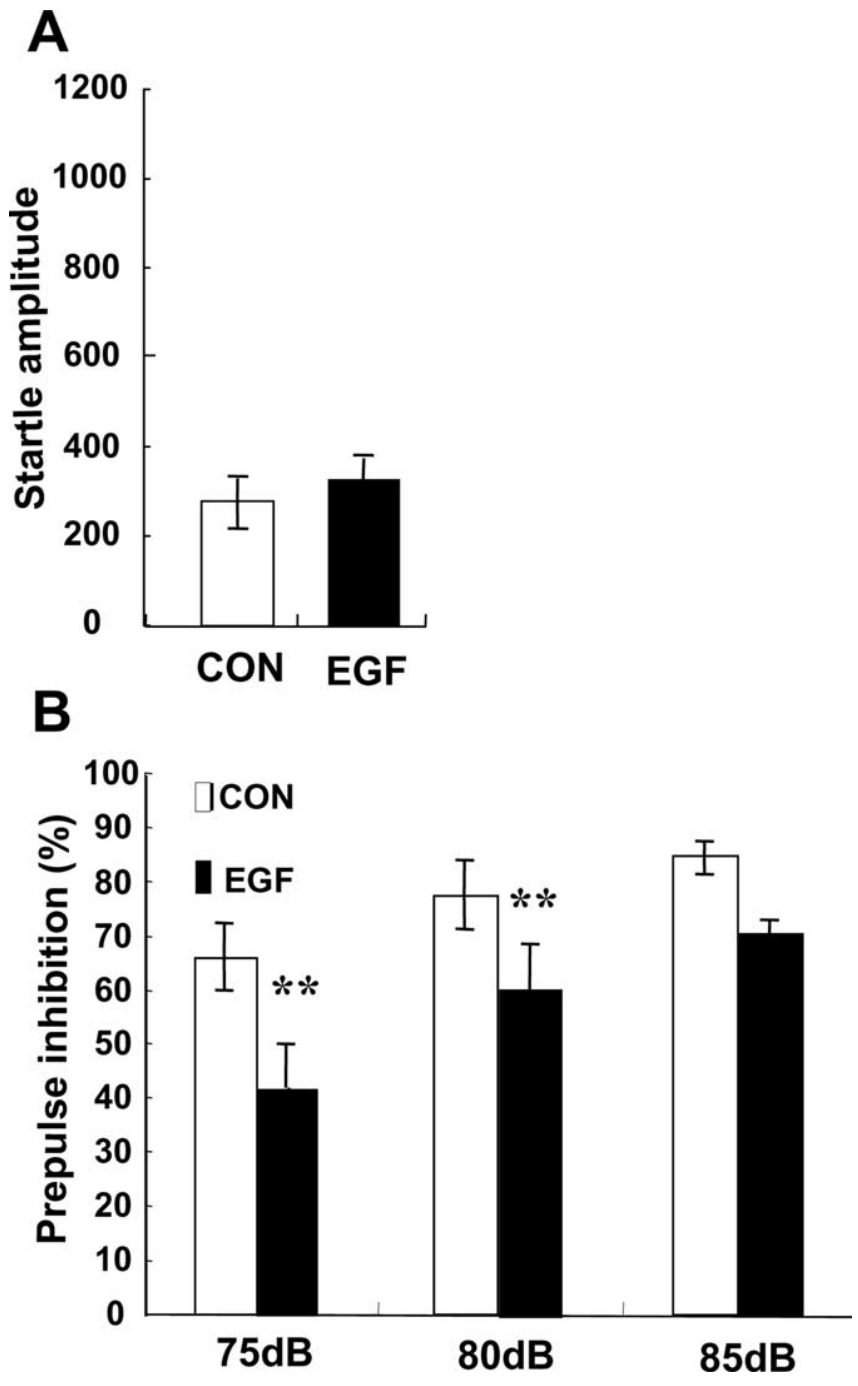

Figure 4. Effects of bilateral EGF infusion on acoustic startle response and PPI. EGF was administered to both hemispheres of the striatum of adult rats from two osmotic minipumps (30 $\mu \mathrm{g} /$ pump $\times 2$ ). A, Acoustic startle response of vehicle-infused control (CON; open box) and EGF-infused (filled box) rats was measured $8 \mathrm{~d}$ after bilateral EGF administration was initiated. $\boldsymbol{B}$, Simultaneously, PPI of vehicle-infused control (open box) and bilaterally EGF-infused (filled box) animals with 75,80 , and $85 \mathrm{~dB}$ prepulse stimuli was measured. Error bars indicate means \pm SEM ( $n=6$ each). ${ }^{* *} p<0.01$ by Fisher's LSD.

Effects of EGF administration to the nucleus accumbens on prepulse inhibition

We also monitored the subchronic effects of EGF administration to the nucleus accumbens, a locus most implicated in PPI regulation (Swerdlow et al., 1990, 2001; Swerdlow and Geyer, 1998). Immunohistochemistry revealed that EGF immunoreactivity was predominantly localized around the nucleus accumbens as well as along the cannula route (Fig. 5A). There was no significant difference in acoustic startle responses between saline- and EGFinfused rats (Fig. 5B). A two-way repeated ANOVA of PPI scores revealed no main effect of EGF treatment but a significant effect of prepulse amplitude $\left(F_{(2,28)}=47.0 ; p<0.0001\right)$ without their interaction (Fig. $5 C$ ). Thus, the administration of EGF to the nucleus accumbens failed to influence PPI levels.

Effects of intrastriatal EGF infusion on neurochemical markers

To assess the neurochemical consequences of striatal EGF infusion, we examined molecular markers for EGF signaling as well as 
A

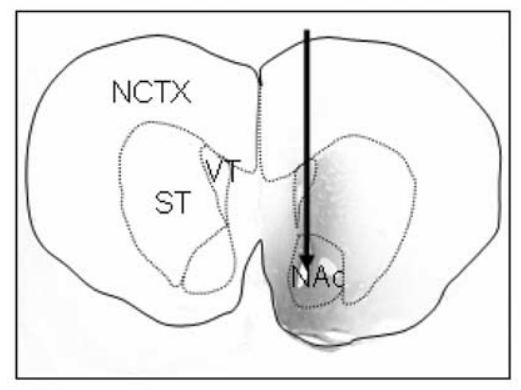

C

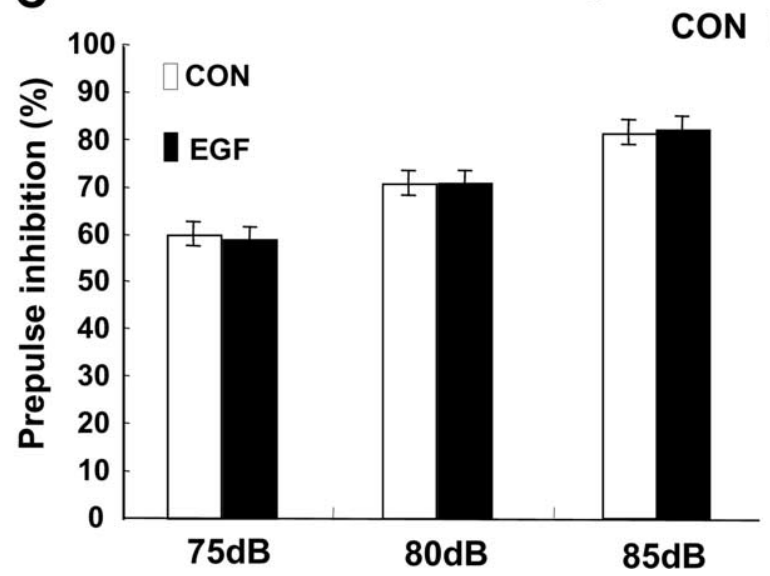

Figure 5. Effects of EGF infusion into the nucleus accumbens on PPI. EGF was administered to the nucleus accumbens of adult male rats from an osmotic minipump ( $30 \mu \mathrm{g} /$ pump) for $8 \mathrm{~d}$. $A$, The efficacy of EGF infusion to the nucleus accumbens was examined by immunohistochemistry. Coronal sections along the cannula route were immunostained with an anti-human EGF antibody. B, Acoustic startle response of vehicle-infused control (CON; open box) and EGFinfused (filled box) rats was measured before fixation for the above immunohistochemistry. PPI of vehicle-infused control and EGF-infused animals was determined with 75, 80, and $85 \mathrm{~dB}$ prepulse stimuli (C). Error bars indicate means \pm SEM ( $n=11$ each). NCTX, Neocortex; ST, striatum; VT, lateral ventricle; NAc, nucleus accumbens. An arrow indicates the cannula position.

those for dopamine signaling in the striatum (Fig. 6). EGF administration significantly elevated phosphorylation levels of ErbB1 (to 137\%; two-tailed $t$ test, $p<0.001$ ) and conversely downregulated total protein levels of ErbB1 (to $61 \% ; p=0.039$ ). As indicated in the above immunohistochemistry, EGF administration upregulated total protein levels of Cox-2 (to 262\%; $p=$ $0.006)$. In parallel, DAT levels were increased $(179 \% ; p=0.041)$, although there were no significant changes in the expression of dopamine receptors, the synaptic marker synaptophysin, or tyrosine hydroxylase (Fig. 6).

\section{A Cox-2 inhibitor ameliorates the EGF-induced deficit of prepulse inhibition}

To evaluate the contribution of Cox- 2 induction to the PPI deficit, rats were simultaneously given a Cox-2 inhibitor, celecoxib $(10 \mathrm{mg} / \mathrm{kg}$, p.o.). Prepulse inhibition of vehicle-infused and EGFinfused animals was examined $1 \mathrm{~h}$ and $7 \mathrm{~d}$ after celecoxib or saline treatment was initiated (Fig. 7). In the acute paradigm of celecoxib administration, the effect of the Cox- 2 inhibitor on PPI was analyzed by three-way ANOVA using between-subject factors of EGF [in its absence or presence $(+/-)$ ] and celecoxib $(+/-)$ and a within-subject factor of prepulse intensity (Fig. 7A). Celecoxib failed to exhibit a main effect on PPI levels, although main effects

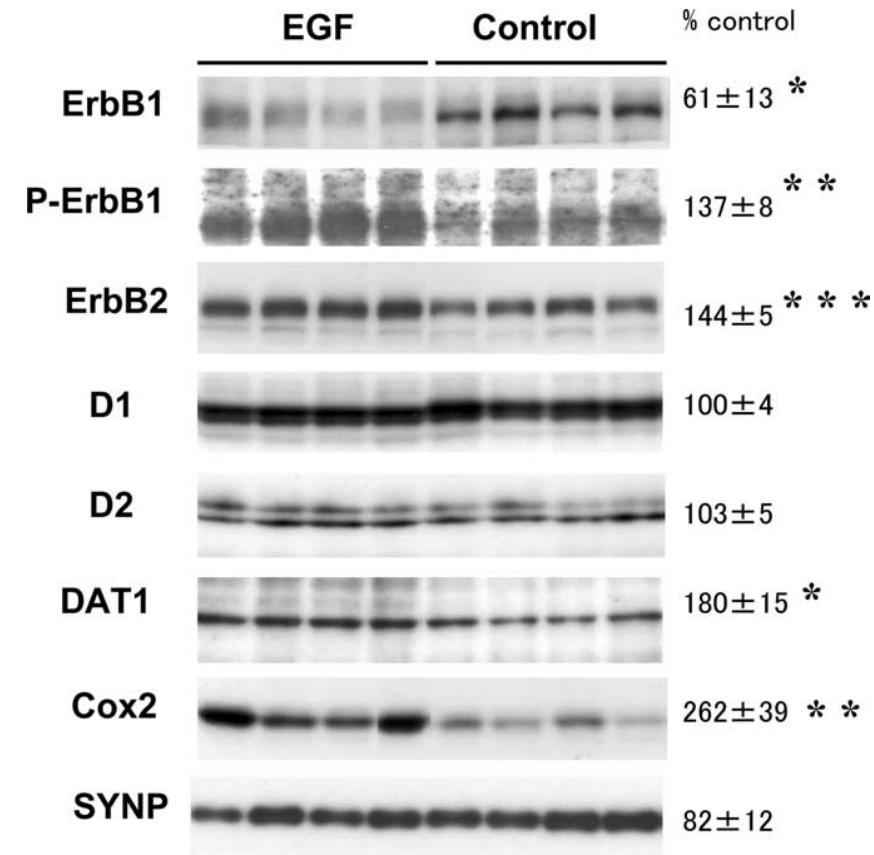

TH

$92 \pm 12$

Figure 6. ErbB1 phosphorylation and neurochemical markers induced by EGF administration. EGF (30 $\mu \mathrm{g} /$ pump) or saline was administered into the striatum of adult rats $(n=4$ animals each). On day 12 of the EGF infusion, protein extract was prepared from the ipsilateral striatum and subjected to immunoblotting for antibodies directed against ErbB1, phosphorylated ErbB1, ErbB2, DAT, D receptor, D receptor, synaptophysin (SYNP), tyrosine hydroxylase $(\mathrm{TH})$, and Cox-2. Immunoreactivity was measured by densitometric analysis, and its ratio to that in vehicle-infused control rats (mean \pm SEM) is presented. ${ }^{*} p<0.05,{ }^{* *} p<0.01$, ${ }^{* * *} p<$ 0.001 by two-tailed $t$ test ( $n=4$ animals each).

of EGF $\left(F_{(1,26)}=18.9 ; p<0.001\right)$ and prepulse intensity $\left(F_{(2,52)}=\right.$ 63.7; $p<0.001)$ were significant. There were no factorial interactions. Similarly, the subchronic effects of celecoxib administration were evaluated by three-way ANOVA. Although there were significant main effects of $\operatorname{EGF}\left(F_{(1,17)}=8.59 ; p=0.009\right)$ and celecoxib $\left(F_{(1,17)}=9.39 ; p=0.007\right)$, ANOVA detected a significant interaction between EGF and celecoxib $\left(F_{(1,17)}=11.2 ; p=\right.$ $0.004)$, suggesting that the therapeutic effects of celecoxib significantly differ between EGF-infused and vehicle-infused animals. Accordingly, the effects of celecoxib were separately evaluated in either the vehicle-infused or EGF-infused group. ANOVA revealed no significant main effect of celecoxib in the vehicleinfused group (Fig. $7 B$ ). In contrast, celecoxib administration to EGF-infused animals improved PPI scores significantly $\left(F_{(1,13)}=\right.$ 2.61; $p<0.001$ ) (Fig. 7C).

Effects of celecoxib treatment on fear learning and its latent inhibition of EGF-infused rats

We also evaluated the effects of striatal EGF infusion and celecoxib on fear learning and latent inhibition. EGF- and vehicleinfused rats were subjected to an active-avoidance test with a two-way shuttle chamber in the presence or absence of preexposure to a buzzer tone (CS) (Salmi et al., 1994). Initial four-way ANOVA using between-subject factors of EGF infusion $(+/-)$, celecoxib administration $(+/-)$, and preexposure to CS $(+/-)$ and a within subject factor of test block (six) revealed significant interactions between EGF and preexposure $\left(F_{(1,72)}=7.65 ; p=\right.$ $0.007)$ and between pre-exposure and block $\left(F_{(5,360)}=5.27 ; p<\right.$ 

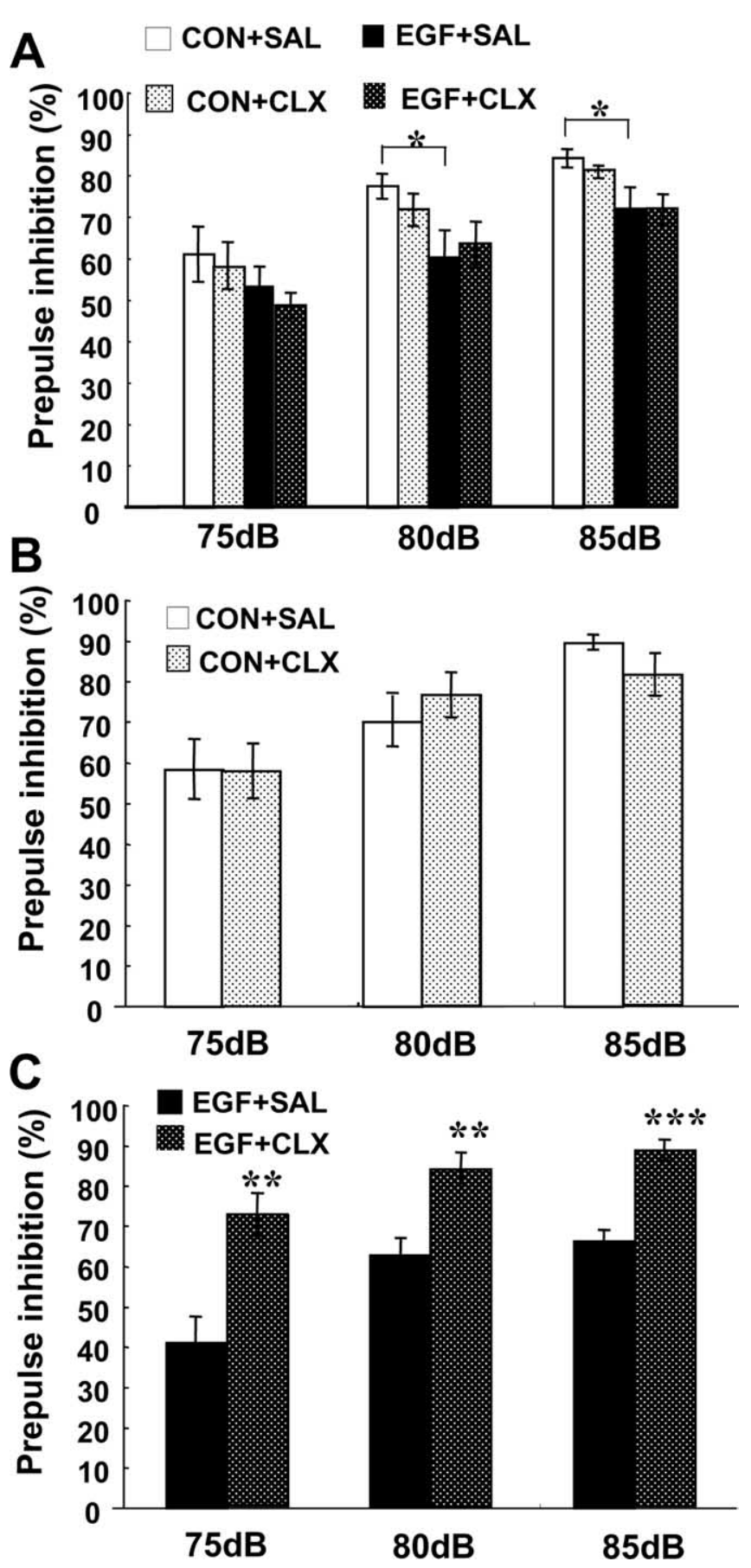

Figure 7. Effects of a Cox-2 inhibitor on the PPI deficits of rats receiving EGF in the striatum. Three days after striatal administration of EGF (30 $\mu \mathrm{g} / \mathrm{pump}$ ) or vehicle (CON) was initiated, rats were orally given celecoxib (CLX) or saline (SAL) daily. $A$, One hour after the first dose of celecoxib, PPI of the acoustic startle response with 75,80 , and $85 \mathrm{~dB}$ prepulse stimuli was measured. $B, C, A t 7 \mathrm{~d}$ of treatment with celecoxib or saline, PPI was measured in vehicle-infused $(\boldsymbol{B})$ and EGF-infused $(\boldsymbol{C})$ rats. White and black bars represent vehicle-infused and EGF-infused rats that received saline orally. Black dotted and white dotted bars represent vehicle-infused and EGFinfused rats that received celecoxib orally. Error bars indicate means \pm SEM for each prepulse intensity $\left(n=7-8\right.$ each). ${ }^{*} p<0.05,{ }^{* *} p<0.01,{ }^{* * *} p<0.001$ compared with saline-infused controls $(\boldsymbol{A})$ or EGF-infused rats receiving saline $(\boldsymbol{C})$ by Fisher's LSD. Note that the subchronic effects of celecoxib were measured at least $20 \mathrm{~h}$ after the last treatment with celecoxib.

0.001). No other interactions were observed among betweensubject factors. The statistical interactions indicated that EGF differentially affected the latent learning scores and that the preexposure effects varied during test sessions. Accordingly, behav- ioral scores were separated into EGF-infused and vehicle-infused groups and subjected to statistical analysis independently.

A three-way-ANOVA of learning data from the vehicleinfused group revealed a significant main effect of preexposure $\left(F_{(1,36)}=22.9 ; p<0.001\right)$ without any interaction of betweensubject factors. The significant interaction between preexposure and block indicated that the effect of preexposure differed among blocks $\left(F_{(5,180)}=3.79 ; p=0.027\right)$ (Fig. 8 A). Post hoc comparisons detected a significant effect of preexposure on learning regardless of celecoxib treatment in blocks 4-6 (Fig. 8A). In contrast, the same analysis for EGF-infused group revealed a significant main effect of preexposure $\left(F_{(1,36)}=10.7 ; p=0.023\right)$, marginal interactions between preexposure and celecoxib $\left(F_{(1,36)}=3.31 ; p=\right.$ $0.077)$, and marginal interactions between preexposure and ses$\operatorname{sion}\left(F_{(5,180)}=1.98 ; p=0.083\right)$. Pillai compensation for repeated measures confirmed statistical significance of the interaction between celecoxib and block $\left(F_{(5,180)}=2.693 ; p=0.039\right)$. Post hoc comparisons revealed that celecoxib treatment significantly improved learning scores of the preexposure group but not the nonpreexposure group in block 6 compared with the vehicle-treated non-preexposure group (Fig. $8 B$ ). Neither EGF infusion nor celecoxib treatment appeared to alter locomotion as monitored by the number of intershuttle movements during the intertrial periods (see details in legend of Fig. 8). We focused on behavioral performance during the last test session and calculated the decrease in learning score that was caused by preexposure to the test chamber without a shock (Fig. $8 C$ ). A two-way ANOVA with subject factors of EGF administration $(+/-)$ and celecoxib treatment $(+/-)$ revealed significant interactions between EGF and celecoxib for this latent inhibition score $\left(F_{(1,18)}=13.1 ; p=\right.$ 0.002). Post hoc comparisons confirmed that striatal EGF infusion disrupted the latent inhibition of fear learning $(p=0.002)$, and subchronic treatment of celecoxib ameliorated the abnormal decrease in latent inhibition $(p=0.002)$.

To assess the effect of EGF infusion on basal fear learning performance, behavioral data were separated into nonpreexposed and preexposed groups to avoid the statistical interaction. In non-preexposed group, three way-ANOVA using between-subject factors of EGF infusion $(+/-)$ and celecoxib administration $(+/-)$ and a within-subject factor of test block (six) revealed that there was not a significant main effect of EGF or celecoxib, and there was no interaction of between-subject factors.

To confirm the ineffectiveness of EGF and celecoxib on basal learning performance and shock sensitivity, we performed another fear learning test (Fig. 9). EGF- and vehicle-infused rats, which were treated with saline or celecoxib, were subjected to contextual conditioning with electric shocks (CS) and environmental context (US). Two-way ANOVA failed to detect a significant difference in shock sensitivity among groups without interaction (Fig. 9A). Learning performance was also indistinguishable among groups (Fig. $9 B$ ). Thus, we conclude that neither striatal EGF infusion nor celecoxib treatment influence basal learning performance or shock sensitivity.

\section{EGF activates dopamine synthesis and turnover}

Deficits in PPI and latent inhibition are proposed to involve abnormal dopaminergic neurotransmission (Swerdlow et al., 2001; Jeanblanc et al., 2003; Smith et al., 2007). To evaluate the contribution of Cox-2 induction to EGF-enhanced dopamine turnover, we also examined the effects of the Cox-2 inhibitor celecoxib on striatal concentrations of dopamine and its metabolites (Fig. 10). A two-way ANOVA with subject factors of EGF admin- 

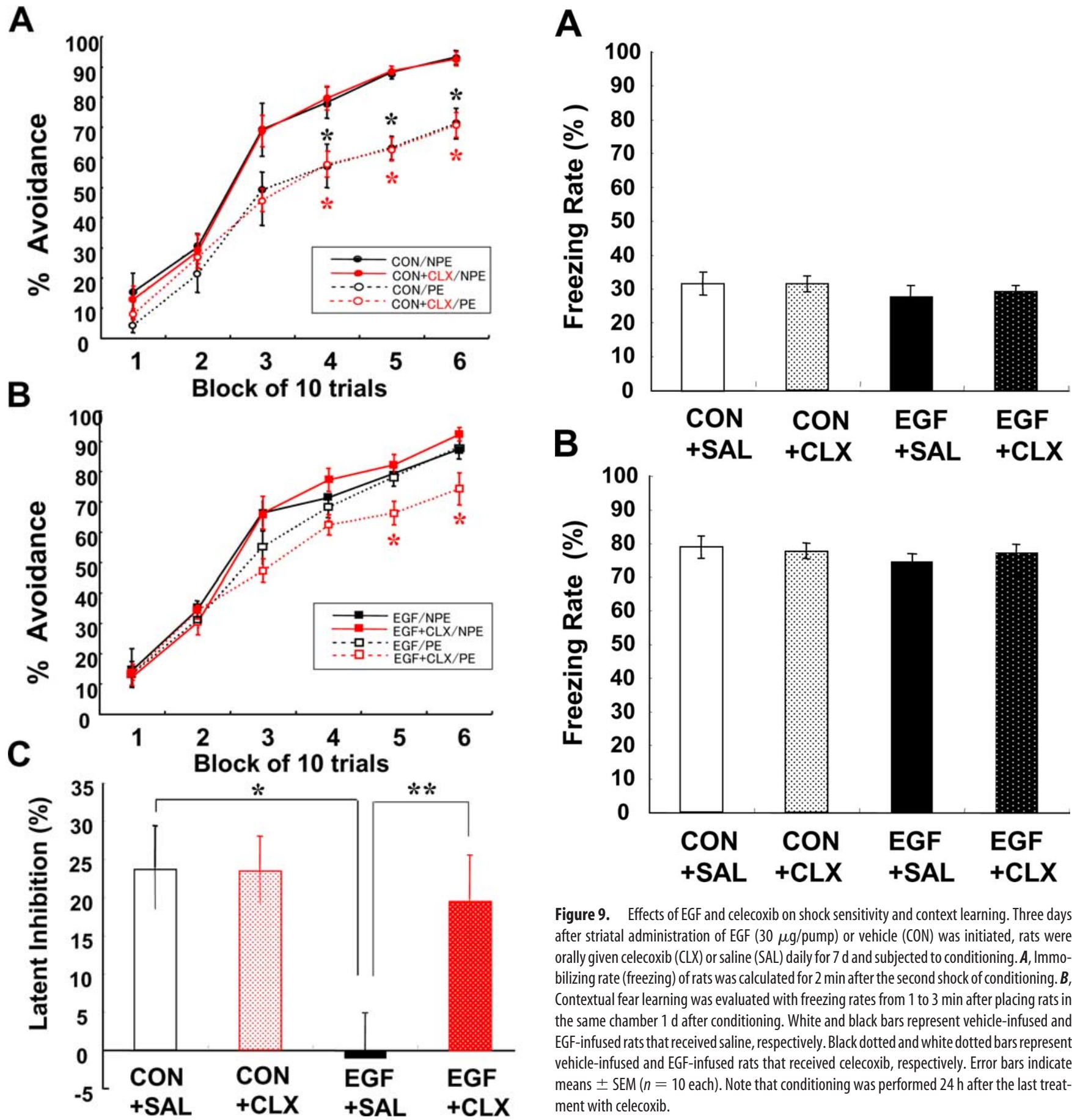

Figure 9. Effects of EGF and celecoxib on shock sensitivity and context learning. Three days after striatal administration of EGF (30 $\mu \mathrm{g} / \mathrm{pump}$ ) or vehicle (CON) was initiated, rats were orally given celecoxib (CLX) or saline (SAL) daily for $7 \mathrm{~d}$ and subjected to conditioning. $A$, Immobilizing rate (freezing) of rats was calculated for $2 \mathrm{~min}$ after the second shock of conditioning. $\boldsymbol{B}$, Contextual fear learning was evaluated with freezing rates from 1 to $3 \mathrm{~min}$ after placing rats in the same chamber $1 \mathrm{~d}$ after conditioning. White and black bars represent vehicle-infused and EGF-infused rats that received saline, respectively. Black dotted and white dotted bars represent vehicle-infused and EGF-infused rats that received celecoxib, respectively. Error bars indicate means \pm SEM ( $n=10$ each). Note that conditioning was performed $24 \mathrm{~h}$ after the last treatment with celecoxib.

Figure 8. The effects of celecoxib on active-avoidance learning and latent inhibition in EGF-infused rats. Learning ability and latent inhibition of EGF-infused rats (EGF; $30 \mu \mathrm{g} /$ pump) was determined with an active-avoidance test (10 trials per block, 6 blocks total) and compared with that of vehicle-infused controls (CON). Simultaneously, these animals were daily treated with celecoxib (CLX) or saline (SAL). Detailed schedules of the EGF infusion and celecoxib are described in Materials and Methods. The ability of vehicle- and EGF-infused rats to avoid the electrical shock paired with a tone was defined as learning performance and improved significantly during training sessions. Before the conditioning, rats in the PE group had been preexposed to the same tone cues without shock. Rats in the NPE group were directly subjected to the active-avoidance test. Random shuttle movement of the NPE group during intertrial periods revealed no effects of EGF by ANOVA or celecoxib or factorial interaction. $A, B$, Because the initial four-way ANOVA revealed factorial interaction between EGF infusion and preexposure, data were separated into vehicle-infused $(\boldsymbol{A})$ and EGF-infused $(\boldsymbol{B})$ groups and then analyzed separately. $\boldsymbol{C}$, Learning performance at the last block (6th) of the PE groups was compared with that of the NPE group and latent inhibition scores were calculated as follows:

istration $(+/-)$ and celecoxib treatment $(+/-)$ revealed significant and marginal interactions between EGF and celecoxib for dopamine and its metabolites, respectively $\left(F_{(1,17)}=4.43, p=\right.$ 0.050 for dopamine; $F_{(1,17)}=3.99, p=0.062$ for DOPAC; $F_{(1,17)}=11.2, p=0.039$ for HVA). Post hoc comparisons revealed that elevated dopamine and HVA contents after EGF administra-

$\leftarrow$

Latent inhibition score $=100-\frac{(\text { performance of each PE rat }) \times 100}{\text { mean performance of NPE group }}$.

Error bars indicate means \pm SEM $\left(n=10\right.$ each). ${ }^{*} p<0.05,{ }^{* *} p<0.01$ by Fisher's LSD. Note that, to minimize acute effects of celecoxib treatment, the active-avoidance test was performed at least $20 \mathrm{~h}$ after the last treatment with celecoxib. 


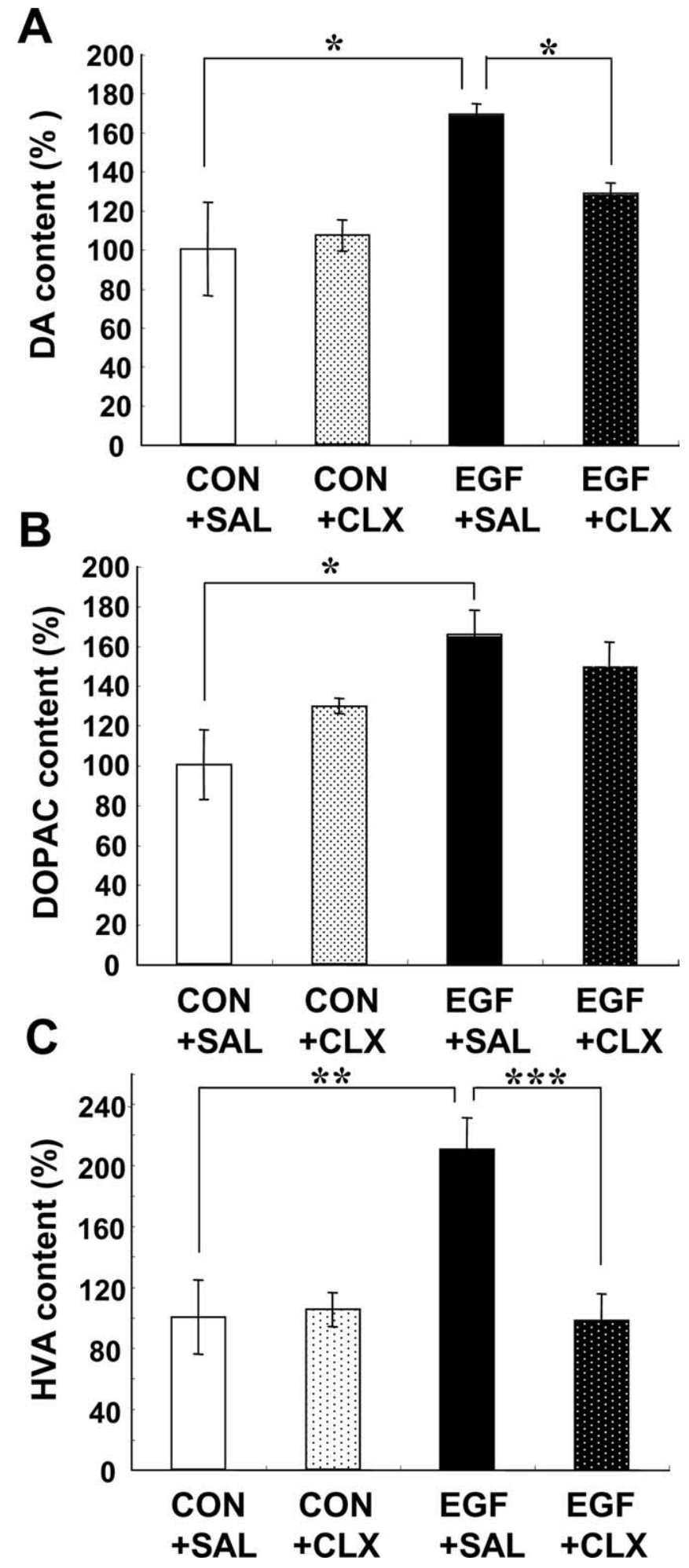

Figure 10. Effects of subchronic celecoxib treatment on dopamine and its metabolites. The levels of dopamine and its metabolites were measured in the striatum of vehicleinfused (CON) and EGF-infused (EGF; $30 \mu \mathrm{g} /$ pump) control rats that also subchronically received celecoxib (CLX) or saline (SAL). Note that, to minimize acute effects of celecoxib treatment, tissue dissection was performed at least $20 \mathrm{~h}$ after the last treatment with celecoxib. White and black bars represent vehicle-infused and EGF-infused rats receiving saline orally. Black dotted and white dotted bars represent vehicle-infused and EGFinfused rats receiving celecoxib orally. Error bars indicate means \pm SEM ( $n=5-6$ each). ${ }^{*} p<0.05,{ }^{* *} p<0.01,{ }^{* * *} p<0.001$ by Fisher's LSD.
Table 2. Effects of EGF infusion and celecoxib on tyrosine hydroxylase activity in the striatum

\begin{tabular}{llll}
\hline & \multicolumn{3}{l}{ Tyrosine hydroxylase activity } \\
\cline { 2 - 4 } & CON-SAL & EGF-SAL & EGF-CLX \\
\hline Dorsal striatum & $9.8 \pm 0.5$ & $12.1 \pm 0.5^{*}$ & $12.3 \pm 0.8^{*}$ \\
Ventral striatum & $9.4 \pm 1.0$ & $12.5 \pm 0.6^{*}$ & $11.7 \pm 0.6^{*}$ \\
\hline
\end{tabular}

EGF (30 $\mu \mathrm{g} /$ pump) or saline (CON) was subchronically administered to the striatum of rats. Some rats were orally given celecoxib (CLX) or saline (SAL) 3 dafter EGF infusion was initiated. The celecoxib treatment was done daily and repeated for $7 \mathrm{~d}$. Tissue homogenates were prepared from the ipsilateral hemisphere of the striatum, and the activity of tyrosine hydroxylase was measured by monitoring the production of L-DOPA. Data represent means \pm SEM (picomoles per milligram of protein; $n=6$ animals each). ${ }^{*} p<0.05$ compared with saline-infused control rats (CON-SAL) by Fisher's LSD.

tion were significantly lowered by subchronic treatment with celecoxib.

How does striatal EGF infusion trigger dopamine-associated behavioral deficits and elevate dopamine levels without changing the expression of the rate limiting enzyme for dopamine synthesis, tyrosine hydroxylase? There are reports that inflammatory cytokines including EGF can elevate the activity of tyrosine hydroxylase by phosphorylating the enzyme or upregulating its cofactor tetrahydrobiopterin (Halegoua and Patrick, 1980; Anastasiadis et al., 1997). We measured the tyrosine hydroxylase activity in the dorsal and ventral striatum of the rats receiving EGF in the striatum (Table 2). The activity of tyrosine hydroxylase in the dorsal striatum of EGF-infused animals was significantly larger than that of saline-infused controls $(p=0.017)$. An increase in the enzymatic activity was also detected in the ventral striatum ( $p$ $=0.012$ ). However, subchronic cotreatment with celecoxib did not attenuate the increase in the activity of tyrosine hydroxylase. We conclude that the increase in dopamine content observed after EGF infusion is, in part, attributable to increased enzymatic activity of tyrosine hydroxylase.

\section{Discussion}

The alterations in inflammatory cytokine levels and the effectiveness of anti-inflammatory drugs observed in schizophrenia patients are consistent with the neuroinflammatory hypothesis of schizophrenia (Muller et al., 2000; Nawa and Takei, 2006). Here we combined the evidence that EGF is an inducer for Cox-2 expression (Ackerman et al., 2004; Slice et al., 2005) with our previous finding that EGF signaling might be upregulated in the striatum of schizophrenia patients (Futamura et al., 2002) and hypothesized that enhanced EGF signaling might increase prostaglandin synthesis and lead to behavioral deficits. Therefore, we tested the neurobehavioral consequences of EGF stimulation in rat striatum as well as the antagonistic effects of Cox-2 inhibition. Subchronic infusion of EGF and concomitant celecoxib treatment produced the following results: (1) striatal infusion of EGF yields behavioral deficits in PPI and latent inhibition of fear learning; (2) these deficits were reversible and extinguished by cessation of EGF infusion; (3) EGF administration elevated the expression of Cox-2, the enzyme activity of tyrosine hydroxylase, and dopamine turnover in the striatum; and (4) subchronic treatment with a Cox-2 inhibitor ameliorated these behavioral deficits and concomitantly normalized dopamine turnover. These observations strengthen the argument that EGF-mediated neuroinflammation may, at least in part, result in abnormal dopamine transmission and associated behavioral deficits.

Enhanced EGF signaling in the striatum and behavioral impairments

The present findings might illuminate the neuropathological implication of abnormal levels of EGF or its receptor in the brain of 
schizophrenia patients (Futamura et al., 2002). The postmortem study demonstrates that, among various ErbB1 ligands, EGF content is specifically decreased in the striatum of schizophrenia patients. Whether this decrease in EGF content reflects enhanced release of EGF from vesicular stores or decreased EGF synthesis is not clear. To address this question, here, we exogenously supplied EGF to the striatum: subchronic infusion of EGF into the striatum induced behavioral impairments. Gross learning ability of EGF-infused rats was normal in active-avoidance test (Fig. 8) as well as in contextual fear conditioning (Fig. 9), however. Abnormalities in PPI as well as in latent inhibition are often observed in schizophrenia patients (Gray et al., 1995; Weiner and Feldon, 1997; Braff et al., 2001; Swerdlow et al., 2001). Accordingly, these results suggest that elevated EGF/ErbB1 signaling in the striatum might contribute to etiology or pathology of schizophrenia.

EGF and other ErbB1 ligands elevate the expression of tyrosine hydroxylase (Casper et al., 1994; Farkas et al., 2002; Iwakura et al., 2005). EGF also modulates the activity of tyrosine hydroxylase by promoting phosphorylation of the enzyme or increasing the synthesis of its essential cofactor tetrahydrobiopterin (Halegoua and Patrick, 1980; Anastasiadis et al., 1997). There was a significant increase in its enzymatic activity in EGF-infused animals. Because this enzyme limits the rate of dopamine synthesis, this increase in enzymatic activity presumably led to an increase in the synthesis and release of dopamine. In this context, the increase in DAT expression might result from enhanced dopamine release through the negative feedback regulation (Xia et al., 1992; Fang and Ronnekleiv, 1999).

Subcutaneous administration of EGF to neonatal rats and mice increases dopamine turnover and later results in life-long neurobehavioral deficits (Futamura et al., 2003; Tohmi et al., 2005). In that experimental paradigm, however, there is a large time lag between the dopaminergic abnormality in neonates and the emergence of the behavioral impairments in adults. Here we learned that striatal EGF infusion to adult animals similarly perturbed dopaminergic responses and mimicked the behavioral deficits induced by neonatal treatment with EGF. Thus, the behavioral deficits induced by neonatal EGF treatment might share a common pathologic mechanism with those of the present striatal EGF infusion, although the persistency of the deficits differs significantly.

\section{Behavioral deficits associated with elevated dopamine synthesis and metabolism}

Consistent with these reports, the present experiments demonstrate that EGF-triggered behavioral abnormalities are concomitant with changes in dopaminergic metabolism in the striatum. EGF administration increases the concentrations of dopamine and its metabolites in the striatum and impaired prepulse inhibition performance in a dose-dependent manner, and, conversely, celecoxib treatment normalized the levels of this neurotransmitter and metabolites, as well as behavioral performance. This elevated dopamine metabolism, but not the increase in the tyrosine hydroxylase activity, was reversed by subchronic treatment with the Cox-2 inhibitor celecoxib. Previous reports demonstrated that prostaglandins influence the activity of excitatory neurons and monoaminergic neurons (Takechi et al., 1996; Oida et al., 1997; Nakamura et al., 2001; Matsuoka et al., 2005; Sang et al., 2005). Given the defined roles of EGF and prostaglandin, we speculate that EGF may increase dopamine synthesis and prostaglandins may enhance its release. These two effects may act synergistically to induce the observed behavioral deficits, although these explanations need to be verified in future experiments including in vivo microdialysis.

\section{Targets of EGF in the brain}

Lesion studies indicate a major contribution of inhibitory striatopallidal circuitry to the acoustic startle reflexes regulating PPI (Swerdlow et al., 1990, 2001). Unilateral dysfunction of this inhibitory circuitry appears to be sufficient to impair PPI responses (Li et al., 1998; Uehara et al., 2007). In agreement with these reports, both unilateral and bilateral infusion of EGF similarly decreased PPI in the present study.

Enhanced dopamine signaling in both ventral and dorsal striatum is implicated in PPI deficits (Kodsi and Swerdlow, 1995; Swerdlow et al., 2001). Among the striatal regions, the nucleus accumbens is suggested to play an important role in regulating PPI (Swerdlow et al., 1990, 2001). Even when EGF was injected to the center of the striatum, EGF immunoreactivity and an increase in the tyrosine hydroxylase activity were also present in the ventral striatum, including the nucleus accumbens. Accordingly, we had expected that EGF infusion directly into the nucleus accumbens would similarly affect PPI. However, it was not the case. We speculate the reasons. Implanting the cannula directly into the nucleus accumbens might produce surgical injury, potentially counteracting the EGF action or perturbing the local neurotransmission. Alternatively, our preliminary result that dopaminergic terminals in the nucleus accumbens express lower levels of ErbB1 may account for the discrepancy (Zheng et al., 2007). Because latent inhibition of learning involves various brain regions and neural circuits including the striatum, the nucleus accumbens, the limbic system, and the cholinergic system (Weiner and Feldon, 1997; Jeanblanc et al., 2003; Peterschmitt et al., 2005), understanding the present discrepancy may require future experiments of greater complexity.

\section{Neurobehavioral and antipsychotic effects of the Cox-2 inhibitor celecoxib}

Significant basal levels of Cox-2 are detectable in several brain regions (Tsubokura et al., 1991; Yamagata et al., 1993; Kaufmann et al., 1996). Inflammatory cytokines induce Cox-2 expression after brain injury, ischemia, and hypoxia (Smith et al., 2000; Ackerman et al., 2004). Increasing Cox-2 expression elevates the levels of all five prostaglandins and activates their downstream receptor signaling (Smith et al., 2000). Conversely, Cox-2 inhibitors attenuate post-ischemic cell death or neurodegeneration associated with Alzheimer's disease (Firuzi and Pratico, 2006). Thus, Cox-2 induction and resultant prostaglandin synthesis are often implicated in neurodegeneration, although the neurotrophic and neurodegenerative actions of prostaglandins remain controversial (Hewett et al., 2000; Strauss and Marini, 2002; Liang et al., 2005). The transgenic mouse model for Alzheimer's disease that overexpresses Cox-2 exhibits age-associated working memory deficits and spatial memory impairment, both of which are sensitive to Cox inhibitors (Sharifzadeh et al., 2005; Melnikova et al., 2006). However, the EGF-induced cognitive deficits in the present study do not appear to involve neurodegeneration because markers for neurons and synapses and brain histochemistry were not altered, the behavioral deficits were reversible, and gross learning scores were normal.

There are several reports demonstrating that the antipsychotic effects and neurocognitive improvement are associated with administration of Cox inhibitors (Ho et al., 2006). Add-on therapy of the Cox-2 inhibitor celecoxib to risperidone improves PANSS of patients with schizophrenia compared with those treated with 
risperidone alone (Muller et al., 2004; Riedel et al., 2005). A follow-up study indicates the most pronounced therapeutic effects of Cox-2 inhibitors are cognitive improvements (Riedel et al., 2005). Nonspecific Cox inhibitors such as indomethacin and piroxicam also reverse behavioral and cognitive deficits induced by cocaine, amphetamines, and brain inflammation (Reid et al., 2002; Ross et al., 2002; Matsumoto et al., 2004). The present study may reveal aspects of the mechanism underlying the effectiveness of this medication protocol. Oral administration of celecoxib for 1 week normalized PPI deficits, whereas a single oral dose failed to do so. Thus, subchronic suppression of Cox-2 activity is required to exert significant effects in this animal model (Rivest, 1999; Carothers et al., 2006). In addition, there was no significant effect of celecoxib on basal PPI levels in control animals, suggesting that basal Cox-2 expression, which is normally present in the corticolimbic system (Tsubokura et al., 1991; Yamagata et al., 1993; Kaufmann et al., 1996), do not influence PPI. Although it remains to be determined which types of prostaglandins contribute to the behavioral and cognitive impairments observed after EGF administration, these experiments support the hypotheses that, in addition to its role in neurological diseases, inflammation-triggered prostaglandin synthesis and signaling are potential therapeutic targets for schizophrenia and related psychiatric disorders.

\section{References}

Ackerman IV WE, Rovin BH, Kniss DA (2004) Epidermal growth factor and interleukin-1beta utilize divergent signaling pathways to synergistically upregulate cyclooxygenase-2 gene expression in human amnion-derived WISH cells. Biol Reprod 71:2079-2086.

Anastasiadis PZ, Bezin L, Imerman BA, Kuhn DM, Louie MC, Levine RA (1997) Tetrahydrobiopterin as a mediator of PC12 cell proliferation induced by EGF and NGF. Eur J Neurosci 9:1831-1837.

Anttila S, Illi A, Kampman O, Mattila KM, Lehtimaki T, Leinonen E (2004) Association of EGF polymorphism with schizophrenia in Finnish men. NeuroReport 15:1215-1218.

Braff DL, Geyer MA (1990) Sensorimotor gating and schizophrenia. Human and animal model studies. Arch Gen Psychiatry 47:181-188.

Braff DL, Geyer MA, Swerdlow NR (2001) Human studies of prepulse inhibition of startle: normal subjects, patient groups, and pharmacological studies. Psychopharmacology (Berl) 156:234-258.

Carothers AM, Moran AE, Cho NL, Redston M, Bertagnolli MM (2006) Changes in antitumor response in C57BL/6J-Min/+ mice during longterm administration of a selective cyclooxygenase- 2 inhibitor. Cancer Res 66:6432-6438.

Casper D, Roboz GJ, Blum M (1994) Epidermal growth factor and basic fibroblast growth factor have independent actions on mesencephalic dopamine neurons in culture. J Neurochem 62:2166-2177.

Das I, Khan NS (1998) Increased arachidonic acid induced platelet chemiluminescence indicates cyclooxygenase overactivity in schizophrenic subjects. Prostaglandins Leukot Essent Fatty Acids 58:165-168.

Denicoff KD, Rubinow DR, Papa MZ, Simpson C, Seipp CA, Lotze MT, Chang AE, Rosenstein D, Rosenberg SA (1987) The neuropsychiatric effects of treatment with interleukin-2 and lymphokine-activated killer cells. Ann Intern Med 107:293-300.

Fang Y, Ronnekleiv OK (1999) Cocaine upregulates the dopamine transporter in fetal rhesus monkey brain. J Neurosci 19:8966-8978.

Farkas LM, Krieglstein K (2002) Heparin-binding epidermal growth factorlike growth factor (HB-EGF) regulates survival of midbrain dopaminergic neurons. J Neural Transm 109:267-277.

Firuzi O, Pratico D (2006) Coxibs and Alzheimer's disease: should they stay or should they go? Ann Neurol 59:219-228.

Futamura T, Toyooka K, Iritani S, Niizato K, Nakamura R, Tsuchiya K, Someya T, Kakita A, Takahashi H, Nawa H (2002) Abnormal expression of epidermal growth factor and its receptor in the forebrain and serum of schizophrenic patients. Mol Psychiatry 7:673-682.

Futamura T, Kakita A, Tohmi M, Sotoyama H, Takahashi H, Nawa H (2003) Neonatal perturbation of neurotrophic signaling results in abnormal sen- sorimotor gating and social interaction in adults: implication for epidermal growth factor in cognitive development. Mol Psychiatry 8:19-29.

Geyer MA, Krebs-Thomson K, Braff DL, Swerdlow NR (2001) Pharmacological studies of prepulse inhibition models of sensorimotor gating deficits in schizophrenia: a decade in review. Psychopharmacology (Berl) 156:117-154.

Gray JA, Joseph MJ, Hemsley DR, Young AMJ, Warburton EC, Boulenguez P, Grigoryan GA, Peters SL, Rawlins JN, Taib CT (1995) The role of mesolimbic dopaminergic and retrohippocampal afferents to the nucleus accumbens in latent inhibition: implications for schizophrenia. Behav Brain Res 71:19-31.

Halegoua S, Patrick J (1980) Nerve growth factor mediates phosphorylation of specific proteins. Cell 22:571-581.

Han C, Michalopoulos GK, Wu T (2006) Prostaglandin E2 receptor EP1 transactivates EGFR/MET receptor tyrosine kinases and enhances invasiveness in human hepatocellular carcinoma cells. J Cell Physiol 207:261-270.

Hanninen K, Katila H, Anttila S, Rontu R, Maaskola J, Hurme M, Lehtimaki $\mathrm{T}$ (2007) Epidermal growth factor a61g polymorphism is associated with the age of onset of schizophrenia in male patients. J Psychiatr Res $41: 8-14$.

Heleniak E, O’Desky I (1999) Histamine and prostaglandins in schizophrenia: revisited. Med Hypotheses 52:37-42.

Hewett SJ, Uliasz TF, Vidwans AS, Hewett JA (2000) Cyclooxygenase-2 contributes to $N$-methyl-D-aspartate-mediated neuronal cell death in primary cortical cell culture. J Pharmacol Exp Ther 293:417-425.

Ho L, Qin W, Stetka BS, Pasinetti GM (2006) Is there a future for cyclooxygenase inhibitors in Alzheimer's disease? CNS Drugs 20:85-98.

Huh YH, Kim SH, Kim SJ, Chun JS (2003) Differentiation status-dependent regulation of cyclooxygenase-2 expression and prostaglandin E2 production by epidermal growth factor via mitogen-activated protein kinase in articular chondrocytes. J Biol Chem 278:9691-9697.

Iwakura Y, Piao YS, Mizuno M, Takei N, Kakita A, Takahashi H, Nawa H (2005) Influences of dopaminergic lesion on epidermal growth factorErbB signals in Parkinson's disease and its model: neurotrophic implication in nigrostriatal neurons. J Neurochem 93:974-983.

Jeanblanc J, Hoeltzel A, Louilot A (2003) Differential involvement of dopamine in the anterior and posterior parts of the dorsal striatum in latent inhibition. Neuroscience 118:233-241.

Kaufmann WE, Worley PF, Pegg J, Bremer M, Isakson P (1996) COX-2, a synaptically induced enzyme, is expressed by excitatory neurons at postsynaptic sites in rat cerebral cortex. Proc Natl Acad Sci USA 93:2317-2321.

Kodsi MH, Swerdlow NR (1995) Prepulse inhibition in the rat is regulated by ventral and caudodorsal striato-pallidal circuitry. Behav Neurosci 109:912-928.

Li L, Priebe RP, Yeomans JS (1998) Prepulse inhibition of acoustic or trigeminal startle of rats by unilateral electrical stimulation of the inferior colliculus. Behav Neurosci 112:1187-1198.

Liang X, Wu L, Hand T, Andreasson K (2005) Prostaglandin D2 mediates neuronal protection via the DP1 receptor. J Neurochem 92:477-486.

Liao HJ, de Los Santos J, Carpenter G (2006) Contrasting role of phospholipase C-gammal in the expression of immediate early genes induced by epidermal or platelet-derived growth factors. Exp Cell Res 312:807-816.

Licinio J, Seibyl JP, Altemus M, Charney DS, Krystal JH (1993) Elevated CSF levels of interleukin-2 in neuroleptic-free schizophrenic patients. Am J Psychiatry 150:1408-1410.

Lin A, Kenis G, Bignotti S, Tura GJ, De Jong R, Bosmans E, Pioli R, Altamura C, Scharpe S, Maes M (1998) The inflammatory response system in treatment-resistant schizophrenia: increased serum interleukin-6. Schizophr Res 32:9-15.

Matsumoto Y, Yamaguchi T, Watanabe S, Yamamoto T (2004) Involvement of arachidonic acid cascade in working memory impairment induced by interleukin-1 beta. Neuropharmacology 46:1195-1200.

Matsuoka Y, Furuyashiki T, Yamada K, Nagai T, Bito H, Tanaka Y, Kitaoka S, Ushikubi F, Nabeshima T, Narumiya S (2005) Prostaglandin E receptor EP1 controls impulsive behavior under stress. Proc Natl Acad Sci USA 102:16066-16071.

Matus-Amat P, Higgins EA, Barrientos RM, Rudy JW (2004) The role of the dorsal hippocampus in the acquisition and retrieval of context memory representations. J Neurosci 24:2431-2439.

McDonald EM, Mann AH, Thomas HC (1987) Interferons as mediators of 
psychiatric morbidity. An investigation in a trial of recombinant alphainterferon in hepatitis-B carriers. Lancet 2:1175-1178.

Melnikova T, Savonenko A, Wang Q, Liang X, Hand T, Wu L, Kaufmann WE, Vehmas A, Andreasson KI (2006) Cycloxygenase-2 activity promotes cognitive deficits but not increased amyloid burden in a model of Alzheimer's disease in a sex-dimorphic pattern. Neuroscience 141:1149-1162.

Miyaoka T, Yasukawa R, Yasuda H, Hayashida M, Inagaki T, Horiguchi J (2007) Possible antipsychotic effects of minocycline in patients with schizophrenia. Prog Neuropsychopharmacol Biol Psychiatry 31:304-307.

Muller N, Riedel M, Ackenheil M, Schwarz MJ (2000) Cellular and humoral immune system in schizophrenia: a conceptual re-evaluation. World J Biol Psychiatry 1:173-179.

Muller N, Riedel M, Scheppach C, Brandstatter B, Sokullu S, Krampe K, Ulmschneider M, Engel RR, Moller HJ, Schwarz MJ (2002) Beneficial antipsychotic effects of celecoxib add-on therapy compared to risperidone alone in schizophrenia. Am J Psychiatry 159:1029-1034.

Muller N, Ulmschneider M, Scheppach C, Schwarz MJ, Ackenheil M, Moller HJ, Gruber R, Riedel M (2004) COX-2 inhibition as a treatment approach in schizophrenia: immunological considerations and clinical effects of celecoxib add-on therapy. Eur Arch Psychiatry Clin Neurosci 254:14-22.

Nakamura K, Li YQ, Kaneko T, Katoh H, Negishi M (2001) Prostaglandin EP3 receptor protein in serotonin and catecholamine cell groups: a double immunofluorescence study in the rat brain. Neuroscience 103:763-775.

Nawa H, Takei N (2006) Recent progress in animal modeling of immune inflammatory processes in schizophrenia: implication of specific cytokines. Neurosci Res 56:2-13.

Oida H, Hirata M, Sugimoto Y, Ushikubi F, Ohishi H, Mizuno N, Ichikawa A, Narumiya S (1997) Expression of messenger RNA for the prostaglandin D receptor in the leptomeninges of the mouse brain. FEBS Lett 417:53-56.

Pai R, Soreghan B, Szabo IL, Pavelka M, Baatar D, Tarnawski AS (2002) Prostaglandin E2 transactivates EGF receptor: a novel mechanism for promoting colon cancer growth and gastrointestinal hypertrophy. Nat Med 8:289-293.

Peterschmitt Y, Hoeltzel A, Louilot A (2005) Striatal dopaminergic responses observed in latent inhibition are dependent on the hippocampal ventral subicular region. Eur J Neurosci 22:2059-2068.

Reid MS, Ho LB, Hsu K, Fox L, Tolliver BK, Adams JU, Franco A, Berger SP (2002) Evidence for the involvement of cyclooxygenase activity in the development of cocaine sensitization. Pharmacol Biochem Behav 71:37-54.

Riedel M, Strassnig M, Schwarz MJ, Muller N (2005) COX-2 inhibitors as adjunctive therapy in schizophrenia: rationale for use and evidence to date. CNS Drugs 19:805-819.

Rivest S (1999) What is the cellular source of prostaglandins in the brain in response to systemic inflammation? Facts and controversies. Mol Psychiatry 4:500-507.

Ross BM, Brooks RJ, Lee M, Kalasinsky KS, Vorce SP, Seeman M, Fletcher PJ, Turenne SD (2002) Cyclooxygenase inhibitor modulation of dopamine-related behaviours. Eur J Pharmacol 450:141-151.

Salmi P, Samuelsson J, Ahlenius S (1994) A new computer-assisted two-way avoidance conditioning equipment for rats: behavioral and pharmacological validation. J Pharmacol Toxicol Methods 32:155-159.

Sang N, Zhang J, Marcheselli V, Bazan NG, Chen C (2005) Postsynaptically synthesized prostaglandin E2 (PGE2) modulates hippocampal synaptic transmission via a presynaptic PGE2 EP2 receptor. J Neurosci 25:9858-9870.
Sharifzadeh M, Naghdi N, Khosrovani S, Ostad SN, Sharifzadeh K, Roghani A (2005) Post-training intrahippocampal infusion of the COX-2 inhibitor celecoxib impaired spatial memory retention in rats. Eur J Pharmacol 511:159-166.

Slice LW, Chiu T, Rozengurt E (2005) Angiotensin II and epidermal growth factor induce cyclooxygenase-2 expression in intestinal epithelial cells through small GTPases using distinct signaling pathways. J Biol Chem 280:1582-1593.

Smith AJ, Li M, Becker S, Kapur S (2007) Linking animal models of psychosis to computational models of dopamine function. Neuropsychopharmacology 32:54-66.

Smith WL, DeWitt DL, Garavito RM (2000) Cyclooxygenases: structural, cellular and molecular biology. Annu Rev Biochem 69:145-182.

Strauss KI, Marini AM (2002) Cyclooxygenase-2 inhibition protects cultured cerebellar granule neurons from glutamate-mediated cell death. J Neurotrauma 19:627-638.

Swerdlow NR, Geyer MA (1998) Using an animal model of deficient sensorimotor gating to study the pathophysiology and new treatments of schizophrenia. Schizophr Bull 24:285-301.

Swerdlow NR, Braff DL, Geyer MA (1990) GABAergic projection from nucleus accumbens to ventral pallidum mediates dopamine-induced sensorimotor gating deficits of acoustic startle in rats. Brain Res 532:146-150.

Swerdlow NR, Geyer MA, Braff DL (2001) Neural circuit regulation of prepulse inhibition of startle in the rat: current knowledge and future challenges. Psychopharmacology (Berl) 156:194-215.

Takechi H, Matsumura K, Watanabe Y, Kato K, Noyori R, Suzuki M, Watanabe Y (1996) A novel subtype of the prostacyclin receptor expressed in the central nervous system. J Biol Chem 271:5901-5906.

Tohmi M, Tsuda N, Mizuno M, Takei N, Frankland PW, Nawa H (2005) Distinct influences of neonatal epidermal growth factor challenge on adult neurobehavioral traits in four mouse strains. Behav Genet 35:615-629.

Toyooka K, Watanabe Y, Iritani S, Shimizu E, Iyo M, Nakamura R, Asama K, Makifuchi T, Kakita A, Takahashi H, Someya T, Nawa H (2003) A decrease in interleukin-1 receptor antagonist expression in the prefrontal cortex of schizophrenic patients. Neurosci Res 46:299-307.

Tsubokura S, Watanabe Y, Ehara H, Imamura K, Sugimoto O, Kagamiyama H, Yamamoto S, Hayaishi O (1991) Localization of prostaglandin endoperoxide synthase in neurons and glia in monkey brain. Brain Res 543:15-24.

Uehara T, Sumiyoshi T, Matsuoka T, Itoh H, Kurachi M (2007) Effect of prefrontal cortex inactivation on behavioral and neurochemical abnormalities in rats with excitotoxic lesions of the entorhinal cortex. Synapse 61:391-400.

Weiner I, Feldon J (1997) The switching model of latent inhibition: an update of neural substrates. Behav Brain Res 88:11-25.

Xia Y, Goebel DJ, Kapatos G, Bannon MJ (1992) Quantitation of rat dopamine transporter mRNA: effects of cocaine treatment and withdrawal. J Neurochem 59:1179-1182.

Yamagata K, Andreasson KI, Kaufmann WE, Barnes CA, Worley PF (1993) Expression of a mitogen-inducible cyclooxygenase in brain neurons: regulation by synaptic activity and glucocorticoids. Neuron 11:371-386.

Zheng H, Iwakura Y, Takada M, Namba H, Takei N, Kakita A, Takahashi H, Nawa H (2007) EGF receptor (ErbB1) expression of nigral dopamine neurons in human and monkey; impact on Parkinsonism. Soc Neurosci Abstr, in press. 